\title{
À SEMELHANÇA DO ANIMAL: MÍMESIS E ALTERIDADE EM ADORNO
}

\author{
Douglas Garcia Alves Júnior \\ dougarcia@rocketmail.com
}

O objeto deste artigo são os textos de Theodor W. Adorno que tematizam a semelhança animal (Tieränlichkeit) do homem. A hipótese que guiará o comentário dos textos é a de que a consciência da afinidade mimética entre animais e homens é a dimensão central que funda a possibilidade de uma concepção emancipatória de racionalidade na obra do filósofo. Nesse sentido, a dimensão mimética presente na constituição do anthropos é referida à co-participação das faculdades estéticas e práticas dos sujeitos, cujas estruturas dizem respeito à relação com a alteridade.

Proponho um percurso que começa na obra escrita com Horkheimer, Dialética do Esclarecimento. Nela, a expressão "semelhança animal do homem" não ocorre. A constelação de temas que cercará esta problemática, contudo, já se esboça claramente no texto. Com efeito, ela comparece, sobretudo, na parte final do livro, "Notas e esboços", especialmente (mas não apenas ${ }^{1}$ ) no aforismo "O homem e o animal". Aforismo que é, significativamente, o mais longo dos vinte e três que compõem esta parte da obra.

1. O tema do animal é significativo também nos aforismos "Para uma crítica da filosofia da história”, "Fragmentos de uma teoria do criminoso", "Le prix du progrès" e "Interesse pelo corpo". 
A aliança ancestral entre razão e dominação da natureza é indicada como fio condutor da história da cultura ocidental, aliança de que a filosofia participa ativamente, ao legitimar o confinamento dos animais nos limites estreitos de objetos disponíveis às operações de autoconservação do sujeito racional. Desejo chamar a atenção, além disso, para dois trechos deste aforismo que alargam essa concepção do animal. Textos, que, a meu ver, propõem uma inversão de perspectivas: ao invés da fala privilegiada da filosofia sobre o animal, apresenta-se a tentativa de circunscrever a sombra que a condição dos animais lança à filosofia e, em última instância, ao pensamento e à razão. Cito o primeiro deles:

In der Tierseele sind die einzelnen Gefühle und Bedürftigkeiten des Menschen, ja die Elemente des Geistes angelegt ohne den Halt, den nur die organisierende Vernunft verleiht (ADORNO\& HORKHEIMER, 1988, p. 263s).

\section{Que Guido de Almeida traduz:}

Na alma do animal já estão plantados os diferentes sentimentos e necessidades do homem e, inclusive, os elementos do espírito, sem o apoio que só a razão organizadora confere (ADORNO\& HORKHEIMER, 2006, p. 203).

\section{Gostaria de propor outra tradução:}

Na alma do animal já estão dispostos os sentimentos e carências² constituintes do homem, e mesmo os elementos do espírito, sem a sustentação ${ }^{3}$ que só a razão organizadora empresta.

Trata-se de pôr em evidência o parentesco que Adorno e Horkheimer assinalam, aqui, entre animalidade, humanidade e fragilidade. Indigência ${ }^{4}$

2. Também caberia a tradução por “indigências” para Bedürftigkeiten, palavra que desempenhará um papel importante no aforismo final de Minima Moralia. Cf. Nota 4, abaixo.

3. Também caberia a tradução por "contenção" para Halt, o que permitiria indicar o caráter de limitação ativa perpetrado pela mesma instância racional que é suporte dos processos espirituais.

4. É a mesma palavra que Adorno emprega no último aforismo das Minima Moralia: "Perspektiven müßten hergestellt werden, in denen die Welt ähnlich sich versetzt, verfremdet, ihre Risse und Schründe offenbart, wie sie einmal als bedürftig und entstellt im Messianischen Lichte daliegen wird.". Na tradução de Luiz Bicca: "Seria produzir perspectivas nas quais o mundo analogamente se desloque, se estranhe, revelando suas fissuras e fendas, tal como um dia, indigente e deformado, aparecerá na luz messiânica" (p. 216) [Minima Moralia. Reflexionen aus dem beschädigten Leben: Zum Ende. Digitale Bibliothek Band 97: Theodor W. Adorno: Gesammelte Schriften, p. 2145 (Cf. GS 4, p. 283)] 
(Bedürfitgkeit) que se manifesta, primeiramente, na ausência de linguagem e de conceito do animal, que o instaura num "vazio lancinante" (bohrend leeren Dasein, literalmente, a "existência cortantemente vazia", Cf. ADORNO\& HORKHEIMER, 2006, p. 263) de uma relação com o tempo que é pura dispersão. Se boa parte da tradição filosófica insistiu sobre a diferença essencial entre a indigência do animal e a autonomia do homem, o texto de Adorno e Horkheimer aponta, diversamente, para a sua comunhão, em um fundo de ausência de linguagem e de dispersão do si no tempo que ameaça o homem e é o destino comum dos animais.

Gostaria de citar outro parágrafo do mesmo aforismo, no qual é aludida a distorção (Verzerrung) como o princípio estético da arte autêntica, que tentaria expressar a desfiguração (Entstellung) que a racionalidade inflige ao animal, bem como à humanidade:

\begin{abstract}
Die Verzerrung, die zum Wesen jedes Kunstwerks gehört, wie das Verstümmelte zum Glanz der weiblichen Schönheit, eben jene Schaustellung der Wunde, in der beherrschte Natur sich wiedererkennt, wird vom Faschismus wieder betrieben, aber nicht als Schein. Sie wird den Verdammten unmittelbar angetan. In dieser Gesellschaft gibt es keinen Bereich mehr, in dem Herrschaft als Widerspruch sich deklarierte wie in der Kunst, keine Verdoppelung drückt mehr die Entstellung aus. Solcher Ausdruck aber hieß ehemals nicht bloß Schönheit, sondern Denken, Geist und Sprache selbst. Sprache heute berechnet, bezeichnet, verrät, gibt den Mord ein, sie drückt nicht aus. (ADORNO\& HORKHEIMER, 1988, pp. 289-290).
\end{abstract}

\title{
Na tradução brasileira:
}

A distorção que pertence à essência da obra de arte, assim como a mutilação pertence ao brilho da beleza feminina, justamente aquela exibição da ferida na qual a natureza se reconhece, foi retomada pelo fascismo, mas não como aparência. Ela é infligida diretamente aos condenados. Nesta sociedade, não existe mais nenhum setor onde a dominação se declare, como na arte, como uma contradição, nenhuma duplicação exprime mais a desfiguração. Essa expressão, porém, não se chamava outrora simplesmente beleza, mas pensamento, espírito e mesmo linguagem. Hoje a linguagem calcula, designa, trai, inspira o assassinato, ela não exprime nada. (ADORNO\& HORKHEIMER, p. 2006, 206s).

Chamo a atenção, em primeiro lugar, para a série que Adorno e Horkheimer constroem:distorção(Verzerrung), deformação(Entstellung, que se poderia traduzir também por desfiguração) e mutilação (das Verstümmelte, que se poderia traduzir também por aquilo que é amputado ou esquartejado). Ela é complementada pela série exibição (Schaustellung, exposição) da beleza feminina, belamente descrita pelos filósofos como exposição da ferida da natureza dominada, pela qual esta 
voltaria a reconhecer-se, aparência (Schein), que é o domínio próprio à obra de arte, e expressão (Ausdruck), elemento próprio da linguagem, comum à arte, ao pensamento filosófico e à vida da consciência, em geral5.

O que desejo ressaltar, nesta passagem, é a maneira pela qual Adorno e Horkheimer conectam os aspectos estéticos da aparência e os elementos éticos da expressão e do pensamento, não a uma suposta primeira natureza intocada, mas, curiosamente, a um princípio de distorção que mimetiza a desfiguração e a amputação que são próprias do que é vivo, tanto dos animais quanto dos seres humanos. Com isso, penso que não só Adorno atribui um papel positivo à mímesis desde a Dialética do Esclarecimento, como também concebe essa mímesis como expressão do que é dissonante no interior das relações entre vida e linguagem, natureza e razão. Voltarei a este ponto mais adiante.

Passo agora a dois trechos em que Adorno emprega a expressão Tieränlichkeit des Menchen, semelhança animal do homem. São ambos retirados de ensaios publicados no livro Prismas: Crítica Cultural e Sociedade. O primeiro encontra-se no ensaio "O ataque de Veblen à cultura". Cito:

In der Zuspitzung der Frage liegt der Ernst des Pragmatisten, dem des Arztes vergleichbar, dessen Hilfsbereitschaft an der Tierähnlichkeit des Menschen ihren Kanon hat. Es ist der Ernst des Todes (ADORNO, 1969, p. 95).

Na tradução brasileira, de Jorge de Almeida e Augustin Wernet: Levando ao extremo esta questão, percebe-se a seriedade do representante do pragmatismo, comparável à do médico que segue o cânone da semelhança entre o homem e o animal. Esta é a seriedade da morte (ADORNO, 1998, $p$. 89).

5. Deve-se chamar a atenção para o fato de que, nas Minima Moralia, Adorno atribui indigência (Bedürftigkeit) e deformação (Entstelltheit) tanto ao mundo quanto ao conhecimento que, do ponto de vista da redenção, dirige-se ao mundo da natureza e da sociedade. Cito: "wäre es auch nur um ein Winziges, entrückt ist, während doch jede mögliche Erkenntnis nicht bloß dem was ist erst abgetrotzt werden muß, um verbindlich zu geraten, sondern eben darum selber auch mit der gleichen Entstelltheit und Bedürftigkeit geschlagen ist, der sie zu entrinnen vorhat" [Minima Moralia. Reflexionen aus dem beschädigten Leben: Zum Ende. Digitale Bibliothek Band 97: Theodor W. Adorno: Gesammelte Schriften, p. 2146 (Cf. GS 4, p. 283)]. Na tradução brasileira de Luiz Bicca "ao passo que todo conhecimento possível não só deve ser obrigatório, mas se vê por isso mesmo marcado pela mesma deformação e pela mesma indigência a que pretende se subtrair" (ADORNO, 1992, p. 216). 
A questão a que Adorno alude é a da novidade qualitativa na história. O contexto dessa passagem é o de uma distinção entre dois tipos de filosofia da história: por um lado, o positivismo, que concebe a história como uma série de ciclos de carência e adaptação, e a dialética, por outro, que pensa o histórico como desenvolvimento de possibilidades não diretamente dedutíveis, seja dos dados isolados de uma determinada situação, seja da configuração do todo social. O médico iguala homens e animais no registro de sua comum facticidade supostamente invariante, anatômico-fisiológica, sobre a qual intervém - daí ele ser comparado, nesta passagem, ao historiador positivista. Ao invés de "animalizar" abstratamente a história, seria preciso "historicizar" o animal, isto é, rever a noção de sua alteridade indeterminada e sem devir.

No mesmo Prismas podemos ler um dos ensaios mais importantes de Adorno, "Anotações sobre Kafka", do qual cito a seguinte passagem:

Anstelle der Menschenwürde, des obersten bürgerlichen Begriffs, tritt bei ihm das heilsame Eingedenken der Tierähnlichkeit, von der eine ganze Schicht seiner Erzählungen zehrt (ADORNO, 1969, p. 285).

Na tradução brasileira, de Jorge de Almeida e Augustin Wernet:

Em vez da idéia de dignidade humana, conceito supremo da burguesia, aparece em Kafka a idéia da salutar semelhança do homem com o animal, presente em grande parte de suas narrativas (ADORNO, 1998, p. 268)

Proponho outra tradução:

Em vez da dignidade humana, conceito supremo da burguesia, aparece em Kafka a curativa rememoração da semelhança ao animal, da qual todo um estrato de suas narrativas se nutre.

Assistimos aqui a uma contraposição entre filosofia e literatura, na qual a verdade filosófica sobre a condição semelhante ao animal dos homens é alcançada pela literatura. A idéia filosófica de dignidade (Würde) remete ao representante supremo do esclarecimento filosófico, $\mathrm{Kant}^{6}$, notadamente à sua filosofia moral, em que a liberdade humana se funda na idéia da absoluta independência do agir moral com relação

6. Cf. Kant, I., Fundamentação da Metafísica dos Costumes: “aquilo, porém, que constitui a condição só graças à qual qualquer coisa pode ser um fim em si mesma, não tem somente um valor relativo, isto é, um preço, mas um valor íntimo, isto é, dignidade" $(B, 77)$. "A natureza racional distingue-se das restantes por se por a si mesma um fim” (B, 82). E, mais adiante, ao distinguir o reino racional e moral dos fins do âmbito mecânico 
às determinações causais da natureza ${ }^{7}$. Segundo a passagem de Adorno, o conceito filosófico de liberdade transcendental seria incapaz de abrir a perspectiva de uma afinidade mimética entre homens e animais, contrariamente ao que é indicado pela narrativa de Kafka. A filosofia deveria pôr-se à altura do estado de consciência alcançado pela arte.

Não seria próprio de um pensamento dialético, no entanto, opor abstratamente "dignidade humana" (Menschenwürde) e "semelhança animal” (Tierähnlichkeit). Assoma aqui, o tema, recorrente em Adorno, da necessidade de uma revisão do transcendental, no sentido da consideração de sua gênese empírica e de seus momentos sociais. Tema que será explorado, em todos os seus desdobramentos, na Dialética Negativa ${ }^{8}$. No ensaio sobre Kafka, trata-se de indicar a atuação de um pensamento rememorador no interior mesmo da arte. Rememoração ${ }^{9}$ (Eingedenken) que aproxima a obra de Kafka da dialética negativa, ao apontar para o imbricamento de materialidade e espírito, de natureza e razão.

Trata-se, portanto, de pensar a dignidade humana na sua semelhança ao animal. Cito, dessa vez, a Teoria Estética, na qual a arte aparece novamente como modalidade de pensamento rememorador:

\begin{abstract}
Nicht so durchaus ist der Gattung Mensch die Verdrängung ihrer Tierähnlichkeit gelungen, daß sie diese nicht jäh wiedererkennen könnte und dabei von Glück überflutet wird; die Sprache der kleinen Kinder und der Tiere scheint eine. In der Tierähnlichkeit der Clowns zündet die Menschenähnlichkeit der Affen; die Konstellation Tier/Narr/Clown ist eine von den Grundschichten der Kunst (ADORNO, 1970, p. 182).
\end{abstract}

da natureza: "Cada ser racional terá de agir como se fosse sempre, pelas suas máximas, um membro legislador do reino universal dos fins. [...] Um reino dos fins só é possível em analogia com um reino da natureza [...] não obstante dá-se também ao conjunto da natureza, se bem que seja considerado como máquina, o nome de reino da natureza, enquanto se relaciona com os seres racionais como seus fins" (B, 84).

7. Cf. uma das passagens centrais da Crítica da Razão Prática: "Nenhuma outra coisa é senão a personalidade, isto é, a liberdade e a independência relativamente ao mecanismo da natureza inteira, ao mesmo tempo, porém, considerada como uma faculdade de um ser que está submetido às leis puras práticas dadas pela sua própria razão” (A 156).

8. Cf. especialmente os parágrafos "Sobre a interpretação do transcendental", "Primado do objeto" e "Determinação dialética da vontade" da Dialética Negativa.

9. Sobre a Eingedenken, ainda que no pensamento de Benjamin, do qual, no entanto, Adorno se nutriu em diversos aspectos, cf. os diversos trabalhos de Jeanne Marie Gagnebin, especialmente: "Teologia e Messianismo no pensamento de W. Benjamin" (1999). 
Na tradução portuguesa de Artur Morão:

O gênero humano não conseguiu um tão pleno recalcamento da sua semelhança com os animais que não a possa reconhecer subitamente e ser então inundado de felicidade; a linguagem das criancinhas e dos animais parece identificar-se. Na semelhança dos clowns com os animais ilumina-se a semelhança humana dos macacos; a constelação animal/louco/clown é um dos estratos fundamentais da arte (TE, p. 140)

O mimético que aparece e se inflama (zündet) na arte, neste trecho, revisita uma experiência ontogenética, a da criança, cuja linguagem é abundantemente gestual e expressiva - características que serão diretamente modeladas e reprimidas, como mostram as agudas análises de Marcel Mauss (2003) sobre as "técnicas do corpo" -, criança que exibe uma tendência a acompanhar mimeticamente as flutuações do ambiente. O prazer e mesmo a felicidade que essa relação mais imediata com a natureza proporciona convive com o medo de ser tragado pela magnitude das forças naturais. Medo também de perder a barreira entre sujeito humano e animal, e ingressar, como o louco, em um mundo sem conceito e sem linguagem. Volto, a esse propósito, ao trecho do ensaio sobre Kafka: como entender a expressão de Adorno, de uma "curativa recordação da semelhança com o animal”? E, ademais, por que essa semelhança animal seria "um dos estratos fundamentais da arte"?

Vejamos. A série animal/criança/louco/clown, neste trecho, é permutável e reversível: as crianças se parecem com os animais, os clowns se parecem com os animais, mas também os animais (macacos) se parecem com os homens, e poderíamos completar o movimento: as crianças se parecem com os homens, e todos eles se parecem com os loucos. Essa rede cruzada parece aludir à primazia de uma dimensão anterior à linguagem plenamente articulada em elementos verbais, uma dimensão eminentemente performativa e mimética da linguagem, da qual os animais participariam, e que evocaria, sobretudo, as polaridades que a criança é capaz de acompanhar: o prazer, o medo, o sofrimento. A dimensão curativa da arte persegue esse fundo opaco de materialidade resistente à linguagem. Talvez sua dimensão propriamente curativa resida no reconhecimento da identidade e não-identidade dos seres humanos com a natureza, que permitiria lidar com a natureza não mais a partir de uma atitude meramente objetivante, mas também performativa, isto é, trazendo-a para uma interação na qual o animal é capaz de responder - e não apenas de reagir, como, com razão, Derrida (2002a, pp. 23-26, 9o) indicou - alcançando uma dimensão de sujeito.

Ao atribuir subjetividade aos animais estaríamos preparados para 
uma relação qualitativamente diversa com a natureza, a qual poderia até mesmo afetar nossa autocompreensão ética como espécie ${ }^{10}$.

Nesse sentido, gostaria de citar e comentar um parágrafo do livro de Adorno sobre Beethoven, que foi publicado no conjunto dos seus escritos do espólio. Trata-se de um texto que se tornou mais conhecido desde que Derrida (2002b) o citou parcialmente, em seu discurso de agradecimento ao receber o Prêmio Adorno, da cidade de Frankfurt, em 2001. Cito o texto de Adorno integralmente:

Ad Beethoven - Was mir an der Kantischen Ethik so suspekt ist, ist die "Würde“, die sie im Namen der Autonomie dem Menschen zuspricht. Die Fähigkeit der moralischen Selbstbestimmung wird dem Menschen als absoluter Vorteil - als moralischer Profit zugeschrieben und insgeheim zum Anspruch der Herrschaft gemacht - der Herrschaft über die Natur. Das ist die reale Seite des transzendentalen Anspruchs, da $\beta$ der Mensch der Natur die Gesetze vorschreibt. Die ethische Würde bei Kant is eine Differenzbestimmung. Sie richtet sich gegen die Tiere. Sie nimmt tendenziell dem Menschen von der Schöpfung aus und damit droht ihre Humanität unablässig in Inhumanität umzuschlagen. Fürs Mitleid läßt sie keinen Raum. Nichts ist dem Kantianer veraßter als die Erinnerung an die Tierähnlichkeit des Menchen. Deren Tabuierung ist allemal im Spiel, wenn der Idealist auf den Materialisten schimpft. Die Tiere spielen fürs idealistische System virtuell die gleiche Rolle wie die Juden fürs faschistische. Den Menschen ein Tier schimpfen - das ist echter Idealismus. Die Möglichkeit der Rettung der Tiere unbedingt um jeden Preis zu leugnen ist die unabdingbare Schranke ihrer Metaphysik. - Die dunklen Züge Beethovens hängen genau damit zusammen (ADORNO, 1993, p. 123s).

\section{Que traduzo por:}

Sobre Beethoven - o que me parece tão suspeito na ética kantiana é a "dignidade" que ele assinala ao homem em nome da autonomia. A capacidade para a autodeterminação moral é atribuída aos seres humanos como uma vantagem absoluta - um ganho moral - enquanto ao mesmo tempo é usada em segredo para legitimar a dominação - dominação sobre a natureza. Este é o aspecto real da reivindicação transcendental de que o homem prescreve as leis da natureza. A dignidade ética em Kant é uma demarcação de diferenças. Ela é dirigida contra os animais. Ela virtualmente exclui o homem da natureza e com isso ameaça incessantemente reverter sua humanidade em inumanidade.

10. Trata-se de uma atitude filosófica partilhada por diversas tendências da filosofia contemporânea. Por exemplo, por Merleau-Ponty, que na "Conferência IV: Exploração do mundo percebido: a animalidade”, de suas Conversas - 1948, discorre a respeito do caráter ativo da experiência do animal, dotado de interioridade, de um centro de 'colocação em forma' do mundo, isto é, de um comportamento de elaboração do meio ambiente (Cf. MERLEAU-PONTY, 2004, p.37s). 
Ela não deixa espaço para a compaixão. Nada é mais execrado pelo kantiano do que a lembrança da semelhança animal do homem. Este tabu sempre está em jogo quando o idealista invectiva contra o materialista. Os animais desempenham para o sistema idealista virtualmente o mesmo papel que os judeus desempenharam para o fascismo. Vituperar o homem de animal - eis o gesto do genuíno idealismo. Negar a possibilidade de salvação para os animais de modo absoluto e a qualquer preço é o limite inalienável de sua metafísica. - E a isto se relacionam os aspectos mais sombrios da obra de Beethoven.

Trecho polêmico, ao qual se pode, sem dúvida, remeter a analogia que Derrida (2002a, p. 52) fará entre os extermínios perpetrados durante o século XX e o abate industrial de gado para o consumo humano - analogia que será retomada na ficção por J.M. Coetzee (2004, p. 72, 75, 106s), em "A vida dos animais". Uma análise mais detida da relação de Adorno com a ética kantiana não poderia ter lugar aqui (Cf. ALVES JÚNIOR, 2005). Proponho tão somente seguir o fio condutor da idéia de que a dignidade humana pensada idealisticamente como puro espírito é um frágil - e cruel - recurso de diferenciação do homem ao animal. E, mais do que isto, de que a separação absoluta homem/animal prolonga um perigo extremo: a de reversão da humanidade em desumanidade, isto é a conversão da dignidade em coisa infinitamente disponível. A idéia de uma "salvação" (Rettung) para os animais é desconcertante, por seu acento teológico. Como é usual em Adorno, seria preciso interpretar o uso deste conceito teológico em sentido materialista. Uma passagem do ensaio sobre Kafka pode nos ajudar, aqui. Ao comentar a pequena narrativa de Kafka, que conta de um sonho em que um homem se vê a si mesmo diante de sua cova, ao lado de um "artista" que desenha o seu nome numa lápide, Adorno escreve: "somente o nome revelado pela morte natural, e não a alma viva, responde pelo que há de imortal no homem" "(ADORNO, 1998, 270). Assiste-se, desse modo, a uma dialética de finitude corpórea e dignidade: esta última reside, contra o anátema idealista, na indigência daquilo que é comum aos homens e animais, no invólucro perecível do corpo.

Retomo, por fim, os três sentidos em que a filosofia de Adorno pensa a semelhança animal do homem, a fim de indicar qual desses sentidos tem prioridade em seu pensamento, bem como relacioná-los a três

11. No original: "Der Name allein, der offenbar wird durch den natürlichen Tod, nicht die lebendige Seele steht ein fürs unsterbliche Teil." (Adorno, Theodor W. "Aufzeichnungen zu Kafka". In: Gesammelte Schriften, GS 10.1, p. 287.) A narrativa de Kafka está traduzida em português. Cf. Kafka, Franz. "Um sonho". In: Um médico rural (1994). 
sentidos de mímesis em sua obra.

Um primeiro sentido de semelhança animal do homem diz respeito à indicação de faculdades e condições presentes no animal, que são comuns também ao homem ou prefiguram aspectos humanos. Essa dimensão de afinidade é remetida, por Adorno, às condições da corporeidade e da mortalidade, no plano das condições comuns a ambos, e às faculdades dos sentimentos (Adorno não escreve meramente sensações, Empfindungen, mas Gefühle) - algo que, sem dúvida, o filósofo deveria ter determinado com mais precisão - e das carências/indigências que ambos carregam, o que diferencia o animal da coisa disponível e o dota de uma autoreferência e de uma capacidade de iniciativa que a filosofia ocidental muitas vezes passou por alto, e não só em sua vertente idealista. A figura da mímesis correspondente a esse plano é a do mimetismo, da mímesis originária, fundada na assimilação do organismo ao espaço circundante.

Um segundo sentido de semelhança animal do homem remete à desfiguração calculada do humano, que o reduz ao mais básico nível de sobrevivência física, o que ocorre na tortura, na privação de liberdade, abrigo e comida, e que é produto da dominação social extremada. Essa redução forçada do homem ao animal age, sobretudo, atingindo a possibilidade de dispor do próprio corpo e de agir a partir de sua própria vontade. A mímesis que é correlata a esse âmbito é o que Adorno, juntamente com Horkheimer, denominou "mímesis da mímesis", nas análises do anti-semitismo como fenômeno mimético na Dialética do Esclarecimento.

Um terceiro sentido de semelhança animal do homem refere-se a uma faculdade humana que se abre a uma aproximação ao animal, sobretudo às dimensões do sofrimento presentes no destino dos animais sob a dominação social da natureza. Penso que este é o sentido mais forte na obra de Adorno, pois se articula a partir da noção de um impulso mimético, imanente à racionalidade, que abre um espaço de identidade e não-identidade, continuidade e descontinuidade, entre sujeito e objeto, corpo e "espírito", linguagem e matéria, enfim, homem e animal. Essa abertura à alteridade se diferencia nas faculdades estéticas e éticas dos seres humanos, lembrando, por fim, os laços que unem racionalidade e mortalidade.

\section{REFERÊNCIAS BIBLIOGRÁFICAS}

ADORNO, Theodor W. Beethoven: Philosophie der neuen Musik. In: Tiedeman, Rolf (ed.) Nachgelassene Schriften, Frankfurt: Suhrkamp, 1993. 
. Kulturkritik und Gesellschaft I/II: Veblens Angriff auf die Kultur. Gesammelte Schriften, 10.1. Frankfurt: Suhrkamp, 1969.

Kulturkritik und Gesellschaft I/II: Aufzeichnungen zu Kafka. Gesammelte Schriften, 10.1 Frankfurt: Suhrkamp, 1969.

. Ästhetische Theorie. Gesammelte Schriften, 7 Frankfurt: Suhrkamp, 1970.

. Minima Moralia: reflexões a partir da vida danificada. Tradução de Luiz Bicca. São Paulo: Editora Ática, 1992.

. Dialética Negativa. Tradução de Marco Antonio Casanova. Rio de Janeiro: Zahar, 2009.

. Prismas: crítica cultural e sociedade. Tradução de Jorge de Almeida e Augustin Wernet. São Paulo: Ática, 1998.

. Teoria Estética. Tradução de Artur Morão. Lisboa: Edições 7o, 1993.

ADORNO, Theodor W.; HORKHEIMER, Max. Dialektik der Aufklärung: philosophische Fragmente. Frankfurt: Fischer, 1988.

; HORKHEIMER, Max. Dialética do Esclarecimento. Tradução de Guido de Almeida. Rio de Janeiro: Zahar, 2006.

ALVES JÚNIOR, Douglas Garcia. Dialética da vertigem: Adorno e a filosofia moral. São Paulo: Escuta/ FUMEC, 2005.

BIRO, Andrew. Adorno and ecological politics. In: BURKE, Donald et al. Adorno and the need in thinking: new critical essays. Toronto: University of Toronto Press, 2007.

COETZEE, J. M. Elizabeth Costello. Tradução de José Rubens Siqueira. São Paulo: Companhia das Letras, 2004.

DERRIDA, Jacques. O animal que logo sou (a seguir). Tradução de Fábio Landa. São Paulo: Editora UNESP, 2002a.

. Fichus: Discours de Francfort. Paris: Galilée, 2002b.

GAGNEBIN, Jeanne-Marie. Teologia e Messianismo no pensamento de W. Benjamin. Estudos avançados, São Paulo, v. 13, n. 37, Dez. 1999.

GERHARDT, Christina. The ethics of animals in Adorno and Kafka. New German Critique N. 97, Winter 2006.

KAFKA, Fraz. Um sonho. In: Um médico rural. Tradução de Modesto Carone. São Paulo: Editora Brasiliense, 1994.

KANT, Immanuel. Crítica da Razão Prática. Tradução de Artur Morão. Lisboa: Edições 70, 1994 .

. Fundamentação da Metafísica dos Costumes. Tradução de Paulo Quintela. Lisboa: Edições 70, 1995.

MERLEAU-PONTY, Maurice. Conversas - 1948. Tradução de Fábio Landa e Eva Landa. São Paulo: Martins Fontes: 2004.

MAUSS, Marcel. As técnicas do corpo. In: Sociologia e antropologia. Tradução de Paulo Neves. São Paulo: Cosac \& Naify, 2003. 


\section{8 - Remate de Males 30.1}

OMBROSI, Orietta. Le Miserere des bêtes: M. Horkheimer et Th W. Adorno face à l'animalité. Paris. Lignes, n. 28, Fev. 2009. 